\title{
SOLUBILITY ENHANCEMENT OF GLIBENCLAMIDE USING MESOPOROUS SILICA
}

\author{
SWATI MITTAL*, AKSHAY SONAWANE, MANGESH KHUNE
}

Department of Vivekanand Education Society's College of Pharmacy, University of Mumbai, Mumbai, Maharashtra, India. Email: swati.mittal@ves.ac.in

Received: 17 May 2019, Revised and Accepted: 30 July 2019

ABSTRACT

Objective: Glibenclamide (GLB) is a Class II drugs encounter the problem of low solubility and low bioavailability. The rate-limiting step for absorption is low solubility, not permeation. Therefore, various approaches in drug formulation development have been used for enhancing solubility and thereby bioavailability of Biopharmaceutical Classification System Class II drugs. These techniques include solid dispersions, complexation using cyclodextrins, self-microemulsifying drug delivery system, hydrotrophy, liquisolid compacts, and adsorption on carriers such as mesoporous silica and Magnesium Aluminometasilicate. Adsorption onto mesoporous silica has demonstrated considerable potential in enhancing the solubility of poorly soluble drugs.

The objective of the present study is to investigate the effect of drug adsorption on SYLOID XDP 3050 carrier complex on the dissolution of GLB tablet.

Methods: A $3^{2}$ full factorial design was adopted to optimize the ratio of GLB (X1) and mesoporous silica as a carrier (X2) and the effect of different ratios was studied on percent yield, percent drug loading, and percent drug release. X-ray powder diffraction and differential scanning calorimetry studies were performed to investigate any possible interaction between GLB and mesoporous silica.

Results: Obtained results of glibenclamide tablets dissolution show that more the amount of carrier taken for adsorption more the drug release in lesser time.

Conclusion: The solubility of GLB was enhanced by loading onto SYLOID ${ }^{\circledR}$ XDP 3050 matrix. Furthermore, the dissolution profile of GLB-loaded SYLOID $^{\circledR}$ XDP 3050-containing tablets was also improved as compared with conventional and commercially available GLB tablets. This study indicates that non-ordered mesoporous SYLOID ${ }^{\circledR}$ XDP 3050 is a promising carrier, which enhances the oral bioavailability of poorly water-soluble drugs.

Keywords: Glibenclamide, Solubility enhancement, Mesoporous silica, Precipitation inhibitor

(c) 2019 The Authors. Published by Innovare Academic Sciences Pvt Ltd. This is an open access article under the CC BY license (http://creativecommons. org/licenses/by/4. 0/) DOI: http://dx.doi.org/10.22159/ajpcr.2019.v12i9.34182

\section{INTRODUCTION}

Oral administration is the most preferred route of drug administration due to convenience, cost-effectiveness, and high patient compliance. All orally administered drugs must be solubilized in the aqueous environment of the gastrointestinal tract before absorption [1]. According to the Biopharmaceutical Classification System (BCS), Class II drugs encounter the problem of low solubility and low bioavailability [2]. The rate-limiting step for absorption is low solubility, not permeation. Therefore, various approaches in drug formulation development have been used for enhancing solubility and thereby bioavailability of BCS Class II drugs. These techniques include solid dispersions, complexation using cyclodextrins, self-microemulsifying drug delivery system, hydrotrophy, liquisolid compacts, and adsorption on carriers such as mesoporous silica and Magnesium Aluminometasilicate $[3,4]$. Adsorption onto mesoporous silica has demonstrated considerable potential in enhancing the solubility of poorly soluble drugs [5]. The drugs can exist in an amorphous or molecularly dispersed state on the surface of mesoporous silica, thus displaying higher apparent solubility and dissolution compared to the crystalline substance $[6,7]$.

Supersaturation is one of the prominent strategies to enhance intestinal absorption of a poorly soluble drug [8]. To exploit the strategy, two steps are essential; generation and maintenance of supersaturation described the concept of "spring and parachute" approach to promote and maintain supersaturation of high energy amorphous forms of drugs in solution [9]. The high energy amorphous form of the drug (spring) can induce the generation of a supersaturated solution in the gastrointestinal lumen. However, supersaturated drug solutions are thermodynamically unstable and have a tendency to return to equilibrium state by drug precipitation. To inhibit drug precipitation and gain benefit from the supersaturated state, the increased concentration has to be maintained for a time period sufficient for absorption. Many pharmaceutical excipients can be used as parachutes, such as cellulose derivatives (methylcellulose, hydroxypropyl methylcellulose [HPMC], and hydroxypropyl cellulose), vinyl polymers (polyvinyl acetate, polyvinylpyrrolidone [PVP], and PVP/vinyl acetate), surfactants, and $\beta$-cyclodextrin derivatives. High-energy or rapidly dissolving solid forms of drugs can be generated by altering morphology, particle size, and/or wettability. Solid dispersions, nanoparticles, coground mixtures; the use of inorganic matrices as a carrier, crystalline salt forms, and prodrugs of higher aqueous solubility are some techniques can be used for the formation of high energy amorphous form of drugs in solution [10]

Glibenclamide (GLB) is a sulfonylurea oral hypoglycemic agent belonging to BCS Class II. Its elimination half-life is approximately $2-5 \mathrm{~h}$ after oral administration, and it is $84 \pm 9 \%$ absorbed from GIT, but its bioavailability is low due to its poor solubility and extensive first-pass metabolism in liver [11,12].

The objective of this study was to improve the solubility of GLB using various carriers and incorporating the same into tablet dosage form.

\section{MATERIALS AND METHODS}

Materials

GLB was provided as a gift sample from USV Pharma, Mumbai (India). Syloid FP 244 EU and Syloid XDP 3050 were provided as a gift sample 
from Grace Davison (Grace DmBH, and Co. KG, Germany) and were used as obtained. The other chemicals used for the study were of analytical grade.

\section{Methods}

Physicochemical characterization of GLB

Physicochemical characteristics of GLB were studied, namely, determination of melting point by recording a differential scanning calorimeter (DSC) thermogram, powder X-ray diffraction (PXRD) studies, $\mathrm{pH}$-dependent solubility, flow properties, and determination of calibration curve (CC).

DSC analysis

The calorimetric analysis was carried out using LAB METTLER STAR SW DSC. $10 \mathrm{mg}$ of sample was placed in a closed DSC aluminum pan and was heated at a constant rate of $10^{\circ} \mathrm{C} / \mathrm{min}$ in the temperature range of $30-300^{\circ} \mathrm{C}$ in a dry nitrogen environment.

XRD analysis

The XRD pattern of API was measured with X'Pert PRO MPD X-ray diffractometer using the software X'Pert Data Collector. Radiations were generated from copper K-alpha electrode and filtered through nickel (Ni) filter with a wavelength of $1.5405 \mathrm{~A} 0$ at a power of $45 \mathrm{KV}$ and $40 \mathrm{~mA}$ were used to study X-ray diffraction patterns. The instrument was operated over the $2 \theta$ range of $10-90^{\circ}$.

\section{Flow properties}

Flow properties of GLB were calculated by determining the bulk density, tapped density, and angle of repose. Carr's index (CI) and Hausner's ratio were calculated.

- $\quad$ Bulk density $(\rho B)$

The bulk density of the powder was determined as per the procedure described in IP 2010. It was calculated using the following formula:

Bulk density $(\rho \mathrm{B})(\mathrm{g} / \mathrm{ml})=$ Weight of a sample in grams $/ \mathrm{V} 0$, where $\mathrm{V} 0=$ Bulk volume

\section{- $\quad$ Tapped density $(\rho \mathrm{T})$}

The tapped density of the powder was determined as per the procedure described in IP 2010. Tapped density was calculated using the following formula:

Tapped density $(\rho \mathrm{T})(\mathrm{g} / \mathrm{ml})=$ Weight of a sample in grams $/ \mathrm{Vt}$, where $\mathrm{Vt}=$ Tapped volume

\section{- C}

Compressibility index measures the propensity of the powder to be compressed and also influences the flow properties since it is affected by the interparticle interactions. It is determined according to the procedure described in IP 2010. It is calculated from the following equation:

Compressibility index $=($ Tap density-Bulk density $) /$ Tap density*100

- Hausner's ratio $(\mathrm{H})$

The Hausner's ratio is a number that is correlated to the flowability of a powder or granular material. The Hausner's ratio is calculated by the formula:
$H=\rho B / \rho T$, where, $\rho \mathrm{B}=$ Bulk density, $\rho \mathrm{T}=$ Tapped density.

- $\quad$ Angle of repose $(\theta)$

The angle of repose is a characteristic related to interparticulate friction or resistance to movement between particles. The angle of repose has been defined as the maximum angle possible between the surface of a pile of powder and horizontal plane. It was determined using the fixed funnel method. A weighed amount of drug was poured through a funnel to form a cone. The angle of repose (The inverse tangent of the ratio of the height of the cone and radius of the base of the cone) was determined by measuring the height of the cone of the powder and radius of the base of the cone. It was calculated from the following formula.

$\tan \theta=h / r$, where, $\theta=$ Angle of repose, $h=$ Height of the pile, $r=$ Average radius of the powder cone.

Solubility study

Different buffers of $\mathrm{pH} 1.2,4.5,6.8$, and 7.4 were prepared according to the procedure in USP. Excess amount of drug was added to $10 \mathrm{~mL}$ buffer in separate vials. These vials were then vortexed for $5 \mathrm{~min}$ and shaken for $24 \mathrm{~h}$ on an orbital shaker. The solutions were filtered and diluted appropriately. The samples were analyzed spectrophotometrically (Jascaow) for drug content at $300 \mathrm{~nm}$.

$\mathrm{CC}$

A CC for estimation of the drug was constructed by dissolving the drug in methanol and recording the ultraviolet (UV) absorbance of different concentration of drug solution in the range of 20-100 ppm at $\lambda$ max of $300 \mathrm{~nm}$.

\section{Formation of drug-carrier complex}

The solid dispersion of GLB with PEG 6000

Solid dispersions of GLB were prepared using PEG 6000 by melt congealing method [13]. In this method, the drug was incorporated, into the molten carrier $\left(70 \pm 5^{\circ} \mathrm{C}\right)$, and heated until a homogeneous melt was obtained and then cooled at room temperature. The resulting solid dispersions were stored for $24 \mathrm{~h}$ in desiccators at room temperature then pulverized and sieved.

\section{Inclusion complex of GLB with $\beta$-cyclodextrin}

Inclusion complex of GLB and $\beta$-cyclodextrin was formed by kneading method [14]. In this method, GLB was added to the slurry of $\beta$-cyclodextrins (amount of water taken was twice the weight of powder mixtures) and was kneaded in a mortar for $30 \mathrm{~min}$. The pastes were dried at $45^{\circ} \mathrm{C}$ and sieved through ${ }^{\#} 80$.

\section{Adsorption of GLB on mesoporous silica}

GLB was loaded onto mesoporous silica by impregnation solvent evaporation technique using rotary flash evaporator [15]. A weighed amount of GLB was dissolved in dichloromethane. The solution was transferred in a round bottom flask (RBF). Mesoporous silica was then added to this solution followed by gentle shaking and sonication for $15 \mathrm{~min}$. The RBF was then attached to rotary evaporator and the solvent was evaporated at $57^{\circ} \mathrm{C}$ under vacuum.

Different batches of solid dispersions, inclusion complex, and adsorption onto carriers are portrayed in Table 1.

Table 1: Drug-carrier complexes of GLB

\begin{tabular}{|c|c|c|c|c|c|c|c|c|}
\hline Batches & A1 & A2 & A3 & A4 & A5 & A6 & A7 & A8 \\
\hline Drug & GLB & GLB & GLB & GLB & GLB & GLB & GLB & GLB \\
\hline \multirow[t]{2}{*}{ Carrier } & Syloid & Syloid & Syloid & Syloid & Syloid & PEG & PEG & $\beta$-cyclodextrin \\
\hline & XDP 3050 & XDP 3050 & XDP 3050 & FP 244 & FP 244 & 6000 & 6000 & \\
\hline Amount of drug (g) & 0.5 & 0.5 & 0.5 & 0.5 & 0.5 & 0.5 & 0.5 & 0.5 \\
\hline Amount of carrier (g) & 1 & 2 & 3 & 1 & 3 & 3 & 5 & 0.5 \\
\hline Drug:carrier ratio & $1: 2$ & $1: 4$ & $1: 6$ & $1: 2$ & $1: 6$ & $1: 6$ & $1: 10$ & $1: 1$ \\
\hline
\end{tabular}

GLB: Glibenclamide 
Evaluation of drug-carrier complex

The drug-carrier complexes were assessed for flow properties to determine the enhancement of flow percent drug loading and enhancement of solubility and in vitro drug release.

\section{Evaluation of flow properties}

The drug-carrier complex was evaluated for flow properties, namely, bulk density, tapped density, CI, Hausner's ratio, and angle of repose. The procedure for determining flow properties is as described in the section of flow properties.

\section{Determination of drug loading in drug-carrier complex}

The total amount of drug-loaded in the carrier was quantified by UV spectrophotometry method. Drug loading in drug-carrier complex was evaluated by extracting the drug from the drug-carrier complex in methanol by vigorous shaking followed by centrifugation and appropriate dilution of the supernatant with methanol. These dilutions were analyzed using a UV-spectrophotometer at the $\chi \max$ of $300 \mathrm{~nm}$.

\section{Evaluation of drug release from the drug-carrier complex}

A dissolution test was carried out in $900 \mathrm{ml}$ of phosphate buffer $\mathrm{pH} 7.4$ using the USP type II dissolution apparatus (Lab India DS 800) at $37 \pm 2{ }^{\circ} \mathrm{C}$ and $75 \mathrm{rpm}$ for the duration of $1 \mathrm{~h}$. Aliquots of $5 \mathrm{ml}$ were withdrawn at 5, 10, 20, and $30 \mathrm{~min}$ and filtered, and then suitably diluted. UV absorbance measured at $227 \mathrm{~nm}$. The concentration was estimated from the appropriate $\mathrm{CC}$ constructed in a $\mathrm{pH} 7.4$ buffer solution.

\section{Optimization of selected drug: Carrier complex}

A $3^{2}$ full factorial experimental designs were used, to optimize the amounts of the drug (X1) and carrier (X2). The different ratios were investigated to provide maximum drug dissolved in $30 \mathrm{~min}$. The response variable studied was percent yield (Y1), percent drug loading (Y2), and percent drug dissolved (Y3) at $30 \mathrm{~min}$. Table 2 provides an overview of the design of the study.

All experiments were performed in a randomized manner to eliminate any unknown possible sources of bias. Data obtained from all the formulations were analyzed using the Design Expert Software 9.0.4 and were used to generate the study design and 3D surface plot. The appropriate factorial model was generated for the response variable using the software. Several statistical parameters, including the coefficient of variation, regression coefficient $\left(R^{2}\right)$, and adjusted regression coefficient (adjusted $\mathrm{R}^{2}$ ) provided by Design-Expert software were compared, and the best fit was selected. In addition, analysis of variance (ANOVA) was used to identify significant effects of factors on response regression coefficients. The $\mathrm{F}$ test and $\mathrm{P}$ values were also calculated using the software. Table 3 details on the optimization batches of drug adsorption onto a mesoporous carrier (Syloid XDP 3050). The drug adsorbates were evaluated for drug loading and drug release from drug-adsorbate.

\section{Determination of crystallinity of GLB}

A selected batch of drug-adsorbate was characterized using PXRD and DSC to determine any change in the crystalline character of GLB.

DSC and PXRD were examined to study the polymorphic form (crystalline or amorphous) of pure GLB and GLB that is adsorbed onto Syloid XDP 3050.

DSC analysis was carried out using LAB METTLER STAR SW DSC instruments. $10 \mathrm{mg}$ of a sample was placed in a closed DSC aluminum pan and was heated at a constant rate of $10^{\circ} \mathrm{C} / \mathrm{min}$ in the temperature range of $30-300^{\circ} \mathrm{C}$ under a dry nitrogen environment. The XRD pattern of GLB and GLB:Syloid XDP 3050 was measured with a view to understanding the polymorphic form of GLB in drug adsorbate and its pure form. This was measured with X'Pert PRO MPD X-ray diffractometer using the software X'Pert data collector. The instrument was operated over the $2 \theta$ range of $10-90^{\circ}$.
Determination of surface characteristics of drug adsorbate by scanning electron microscopy (SEM)

The morphology and particle size of the pure GLB and GLB adsorbed Syloid XDP 3050 were examined using SEM. The images of the above samples were viewed under Jeol5400 SEM (Jeol, Japan) after sputter coating with gold in Fine Coat Ion JFC 1100 sputter (Jeol, Japan) for 5-6 min.

\section{Formulation development of tablets using the adsorbed drug}

Amount of drug-adsorbate equivalent to $5 \mathrm{mg} \mathrm{GLB}$ was accurately weighed. Tablet blends were prepared using HPMC E-5 as precipitation inhibitor, sodium starch glycolate, and croscarmellose sodium as superdisintegrant, PVP K30 as dry binder, and microcrystalline cellulose PH 102 as diluents, and magnesium stearate as a lubricant. Required amounts of all excipients other than the lubricants were separately sifted through no. ${ }^{\# 60}$ accurately weighed and mixed with the drug-adsorbate. This was followed by the addition of lubricants. The mixture was blended for about $3 \mathrm{~min}$. The blends were evaluated for flow properties. Lubricated blend was compressed using $6 \mathrm{~mm}$ biconvex punch. Formulations are described in Table 4.

\section{Evaluation of tablets}

Formulated tablets were evaluated for different parameters such as tablet dimensions, weight variation, hardness, friability, and disintegration time, and analytical parameters such as dissolution profile and assay were evaluated. Dissolution of the tablet was carried out in USP apparatus II (Paddle) using $900 \mathrm{ml} \mathrm{pH} 7.4$ phosphate buffer as dissolution medium at $37^{\circ} \mathrm{C}$ at $10,20,30,45$, and $60 \mathrm{~min}$. In vitro release profile of formulated tablet was compared with the marketed tablet.

\section{RESULTS AND DISCUSSION}

\section{Characterization of GLB}

DSC and melting point

The crystalline form of the drug along with its melting point was evaluated by DSC analysis which showed a sharp endothermic peak in the DSC curve indicating the presence of the drug in crystalline form

Table 2: Coding of the actual values for $3^{2}$ full factorial designs

\begin{tabular}{llll}
\hline $\begin{array}{l}\text { Factor } \\
\text { (Independent variable) }\end{array}$ & Levels & & \\
\cline { 2 - 4 } & High (+1) & Medium (0) & Low (-1) \\
\hline Drug (X1) & 33.33 & 20 & 14.28 \\
Carrier (X2) & 85.72 & 80 & 66.66 \\
\hline
\end{tabular}

Dependent variables - \% yield (Y1), \% drug loading (Y2) and \% drug dissolved (Y3) at $30 \mathrm{~min}$

Tablet 3: Composition of batches for optimization of the amount of carrier and amount of drug

\begin{tabular}{llllllllll}
\hline $\begin{array}{l}\text { Independent } \\
\text { variables }\end{array}$ & \multicolumn{10}{c}{ Optimization trials } \\
\cline { 2 - 9 } & F1 & F2 & F3 & F4 & F5 & F6 & F7 & F8 & F9 \\
\hline Amount of GLB & +1 & +1 & +1 & 0 & 0 & 0 & -1 & -1 & -1 \\
Amount of & +1 & 0 & -1 & +1 & 0 & -1 & +1 & 0 & -1 \\
Syloid XDP 3050 & & & & & & & & & \\
\hline
\end{tabular}

Table 4: Formulation and development of glibenclamide immediate release tablet. ( ${ }^{*}$ Quantities in $\mathrm{mg}$ )

\begin{tabular}{lll}
\hline Ingredient & B1 & B2 \\
\hline Drug-adsorbate (equivalent to 5 mg drug) & 35.31 & 35.31 \\
HPMC E-5 & - & 30 \\
PVP-K 30 & 3 & 3 \\
Sodium starch glycolate & 2 & 2 \\
Croscarmellose sodium & 2 & 2 \\
Microcrystalline cellulose PH 102 & 57.49 & 27.49 \\
Talc & 0.2 & 0.2 \\
Total (mg) & 100 & 100 \\
\hline
\end{tabular}


at its melting point $174.27^{\circ} \mathrm{C}$. The endothermic peak of GLB by DSC analysis is represented in Fig. 1. Fig. 1 shows that the procured drug complies with the reported results.

\section{PXRD}

GLB was further analyzed by PXRD to confirm its crystallinity. The diffraction pattern of the crystalline drug GLB is represented in Fig. 2. The appearance of sharp peaks confirmed the crystalline nature of the drug.

\section{Flow properties}

Determination of angle of repose, CI, and Hausner's ratio showed that GLB has very poor flow. The poor flow can be attributed to the fine particle size of the drug. The fine size results in the development of surface charge and adhesive forces that hinder the free-flowing properties of the drug. The results are depicted in Table 5.

\section{Solubility study}

The solubility of GLB was estimated at $\mathrm{pH} 1.2,4.5,6.8$, and 7.4 buffers and water by determination of saturation solubility. Being a weakly acidic drug, GLB showed the highest solubility at basic $\mathrm{pH}$ (about $0.036 \mathrm{mg} / \mathrm{ml}$ ). Table 6 describes the solubility of GLB in different media.
$C C$

CC of GLB was constructed in methanol by recording the absorbance's of $10,20,40,60,80$, and $100 \mu \mathrm{g} / \mathrm{ml}$ and plotting these against the corresponding absorbance values. The regression coefficient value (R2) was calculated. The graph was found to be linear with a R2 value of 0.999 and the straight line equation was found to be $y=0.006 x+0.016$. The absorbance versus concentration CC of GLB in methanol is shown in Fig. 3.

\section{Evaluation of drug-carrier complex}

Different methods were employed for the formation of the drug-carrier complex. The drug-carrier complex was evaluated for flow properties and drug load content and in vitro drug release from drug-carrier complex.

\section{Evaluation of flow properties and drug loading}

The drug-carrier complex was evaluated for flow properties, namely, bulk density, tapped density, CI, Hausner's ratio, and angle of repose as per procedure mentioned in the section of evaluation of flow properties. The results for the flow parameters and drug load content of adsorbed drug are as follows in Table 7. Batch A1, A2, A3, A6, and A8 of the adsorbed drug had excellent flow properties with excellent to fair compressibility index. Batch A4 and A5 showed good flow properties with fair to passable compressibility index. Drug loading in drug-carrier complex was evaluated by the procedure mentioned above. Batch A3 and A6 showed a

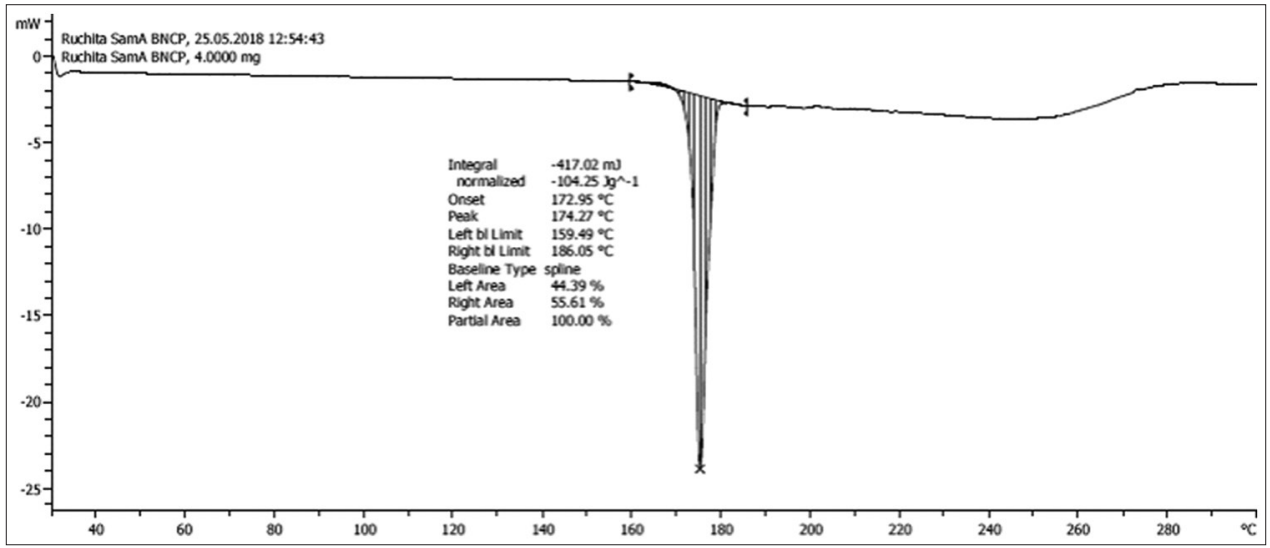

Fig. 1: Differential scanning calorimeter spectrum of glibenclamide showing a sharp endothermic peak

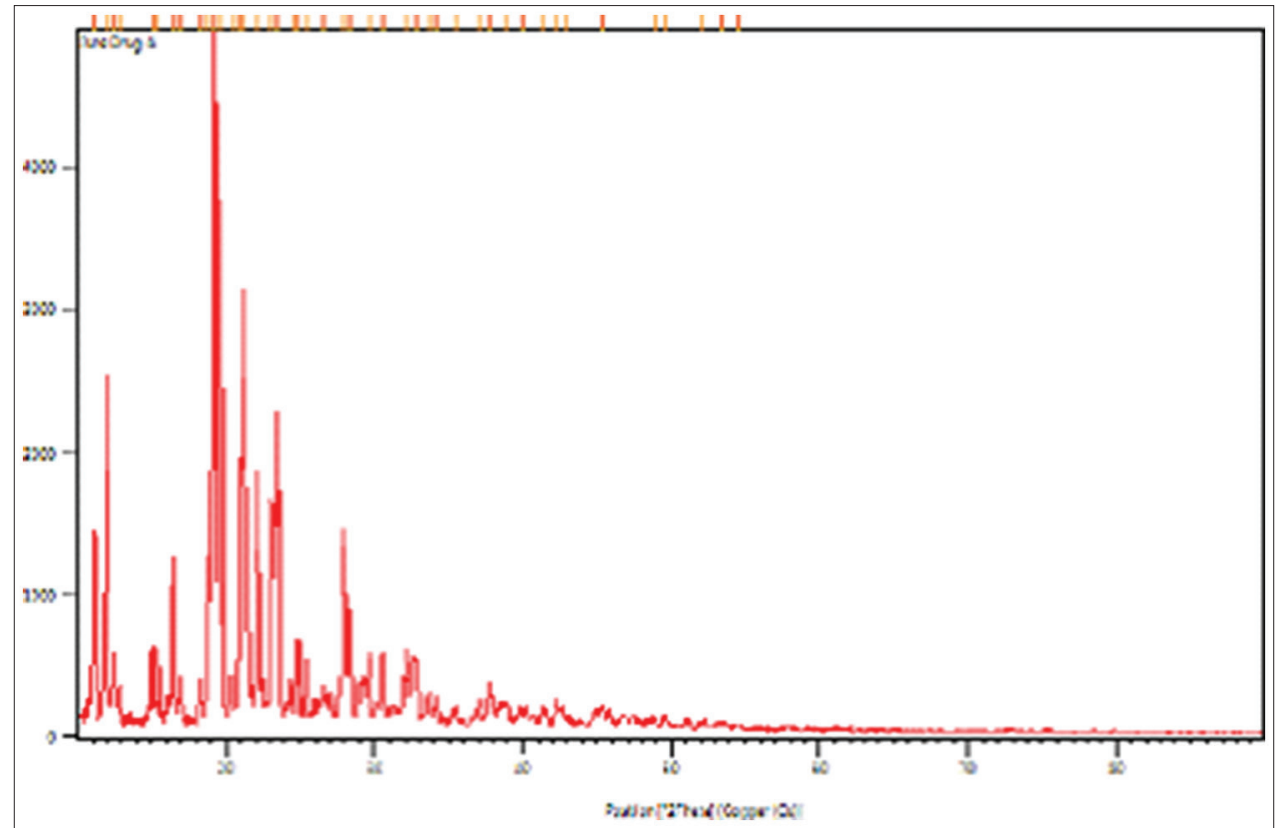

Fig. 2: Powder X-ray diffraction pattern of glibenclamide 
Table 5: Flow properties of GLB

\begin{tabular}{llll}
\hline Flow properties & Observations & Inference & $\begin{array}{l}\text { Reference } \\
\text { range }\end{array}$ \\
\hline Bulk density $(\mathrm{g} / \mathrm{ml})$ & 0.2 & - & - \\
Tapped density $(\mathrm{g} / \mathrm{ml})$ & 0.28 & - & - \\
Carr's index $(\%)$ & 28.57 & Poor flow & $28-35$ \\
Hausner's ratio & 1.4 & Poor flow & $1.35-1.45$ \\
Angle of repose $\left(^{\circ}\right)$ & $33.1^{\circ}$ & Good & $31-35^{\circ}$ \\
\hline
\end{tabular}

Table 6: Solubility results of GLB in various media

\begin{tabular}{ll}
\hline Medium & Solubility $(\mathbf{m g} / \mathbf{m l})$ \\
\hline Water & 0 \\
pH 1.2 buffer & 0.030 \\
pH 4.5 buffer & 0 \\
pH 6.8 buffer & 0 \\
pH 7.4 buffer & 0.036 \\
\hline
\end{tabular}

GLB: Glibenclamide

higher percent drug loading than other batches. Batch A3 had GLB:Syloid XDP 3050 (1:6). The higher concentration of carrier resulted in better entrapment in the mesoporous structure. In A4 and A5, GLB: Syloid FP244 was used in 1:2 and 1:6 ratio. The percent drug loading was comparable to XDP 3050. Percent drug loading in A4 was 89.57\% and A5 was $93.53 \%$. In both A6 and A7, PEG 6000 was used as carrier and percent drug loading was 98.94 and 87.32 , respectively. The higher drug loading is attributed to high carrier concentration in these batches.

Evaluation of drug release from the drug-carrier complex Dissolution studies of all drug-carrier complexes were performed in USP apparatus II (paddle type) using phosphate buffer $\mathrm{pH} 7.4$ as the dissolution medium. Initially, it was observed that the drug desorption was faster from Syloid XDP 3050 and Syloid FP 244 to generate a supersaturated drug solution. However, supersaturated solutions are thermodynamically unstable and have a tendency to return to equilibrium state by drug precipitation. Therefore, the solubility of GLB was rapidly decreased within $5 \mathrm{~min}$. Hence, this problem was overcome using HPMC E-5 as a stabilizer or precipitation inhibitor. HPMC E-5 was physically mixed with drug-carrier complex, and drug release was observed. The drug release from Syloid XDP 3050 and Syloid FP 244 was almost $80 \%$ and $37 \%$, respectively, in just $30 \mathrm{~min}$ which indicates that the drug solubility has been improved to a great extent. Drugs desorption from PEG 6000 and $\beta$-cyclodextrin was found to be less. Plain drug solubility was found to be approximately $2 \%$ at the end of $1 \mathrm{~h}$. Fig. 4 depicts a graphical representation of the dissolution profile of an adsorbed drug. Hence, from the results, Syloid XDP 3050 was selected as a carrier. Since it gave improved flow properties as well as increases the solubility.

\begin{tabular}{ll}
\hline Batch & Drug: Carrier \\
\hline A1 & GLB: Syloid XDP $3050(1: 2)$ \\
A2 & GLB: Syloid XDP $3050(1: 4)$ \\
A3 & GLB: Syloid XDP $3050(1: 6)$ \\
A4 & GLB: Syloid XDP $3050(1: 2)$ \\
A5 & GLB: Syloid XDP $3050(1: 6)$ \\
A6 & GLB: PEG $6000(1: 6)$ \\
A7 & GLB: PEG $6000(1: 10)$ \\
A8 & GLB: $\beta$-cyclodextrin $(1: 1)$ \\
\hline
\end{tabular}

\section{Optimization of drug adsorption using SYLOID XDP 3050}

Drug adsorption was optimized by a $3^{2}$ factorial design. An overview of the experimental trials and the responses obtained is presented in Table 8. The obtained results of drug dissolved at the end of 30 min were fitted in the Design Expert Software 9.0.4 and it was statistically analyzed for the response variable using the same. A total of nine formulations was proposed by $3^{2}$ factorial design for the two independent variables (i.e., Drug X1 and Carrier X2) varied at three different levels [high $(+1)$, medium $(0)$, and low $(-1)]$.

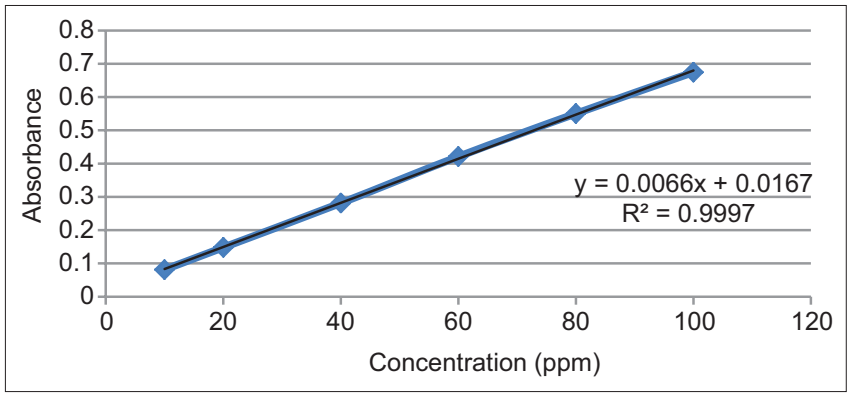

Fig. 3: Ultraviolet calibration curve of glibenclamide in methanol at $\chi \max 300 \mathrm{~nm}$

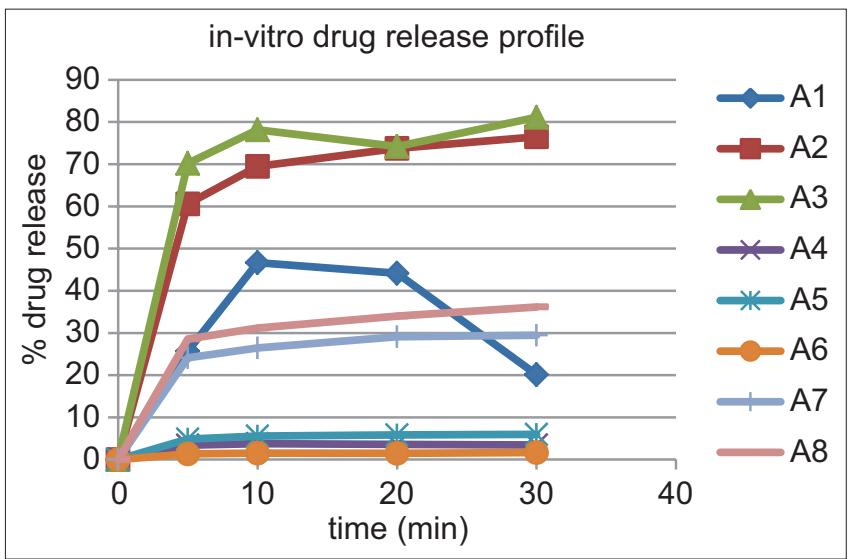

Fig. 4: Graphical representation of dissolution profile of an adsorbed drug

Effect of independent variables (amount of drug and amount of carrier) on dependent variable percent yield

Analysis of the statistical parameters showed that the selected model is significant. The results of the ANOVA for the selected model are shown in Table 9 that indicated that the selected model was significant for the response variable (percent yield) studied. The model F-value obtained was 7.47. In this model, A (drug), B (carrier), and AB (interaction of $\mathrm{A}$ and $\mathrm{B}$ ) are significant model terms. The results of the statistical parameters for the model selected are presented in Table 10.

The optimized model equation for the response variable (Y1) is given as follows:

$\%$ yield at $30 \min (\mathrm{Y} 1)=+96.63+1.33^{*} \mathrm{~A}(\mathrm{drug})+1.83^{*} \mathrm{~B}$ (carrier) $-1.75^{*} \mathrm{~A}$ (drug) ${ }^{*} \mathrm{~B}$ (carrier)

It is observed from the Equation no. 1 that the coefficient b1 and b2 are positive, and coefficient b1b2 is negative. It implies that interaction between drug and carrier has an antagonistic effect on the response variable - percent yield.

The model F-value of 7.47 implies that the model is significant. There is only a $1.38 \%$ chance that an F-value this large could occur due to errors. $\mathrm{p}<0.0500$ indicates that model terms are significant. Precision measures the signal to noise ratio. A ratio $>4$ is desirable. The obtained ratio of 8.569 indicates an adequate signal (model is significant). This model can be used to navigate the design space. Design expert Software generated interaction plot and 3D surface response plot that are represented in Figs. 5 and 6. The interaction plot shows that the high level of the carrier has a positive effect (maximum percent yield) on the response variable at varied levels of drug, whereas the low level of the carrier has a negative effect (minimum percent yield) with the low level of the drug. 
Table 7: Flow properties and percent drug loading of batches

\begin{tabular}{|c|c|c|c|c|c|c|c|c|}
\hline Parameters & A1 & A2 & A3 & A4 & A5 & A6 & A7 & A8 \\
\hline Bulk density (g/ml) & 0.33 & 0.312 & 0.303 & 0.166 & 0.130 & 0.52 & 0.48 & 0.48 \\
\hline Tapped density (g/ml) & 0.416 & 0.370 & 0.333 & 0.217 & 0.178 & 0.59 & 0.56 & 0.65 \\
\hline Carr's index $(\%)$ & 20 & 15.62 & 9.09 & 23.33 & 26.31 & 12 & 14.81 & 25.80 \\
\hline Hausner ratio & 1.24 & 1.18 & 1.09 & 1.30 & 1.35 & 1.13 & 1.16 & 1.34 \\
\hline Angle of repose $\left({ }^{\circ}\right)$ & 26.8 & 23.5 & 22.2 & 32.7 & 30.3 & 23 & 23.3 & 42.82 \\
\hline Flow rate $(\mathrm{s})$ & 0.99 & 0.94 & 0.90 & 1.2 & 0.99 & 0.95 & 0.99 & 3.67 \\
\hline Drug loading (\%) & 96.57 & 93.25 & 99 & 89.57 & 93.53 & 98.94 & 87.32 & 90.64 \\
\hline
\end{tabular}

Table 8: Summary of the $3^{2}$ factorial designs

\begin{tabular}{|c|c|c|c|c|c|c|}
\hline Batch & Run & $\begin{array}{l}\text { Factor } 1 \\
\text { A: Drug Mg }\end{array}$ & $\begin{array}{l}\text { Factor } 2 \\
\text { B: Carrier Mg }\end{array}$ & $\begin{array}{l}\text { Response } 1 \\
\% \text { yield } \%\end{array}$ & $\begin{array}{l}\text { Response } 2 \\
\% \text { drug loading \% }\end{array}$ & $\begin{array}{l}\text { Response } 3 \\
\text { \% drug release \% }\end{array}$ \\
\hline F1 & 1 & +1 & +1 & 99 & 99.32 & 67 \\
\hline F2 & 2 & +1 & 0 & 96 & 99.18 & 64.12 \\
\hline F3 & 3 & +1 & -1 & 98 & 96.57 & 20.12 \\
\hline $\mathrm{F} 4$ & 4 & 0 & +1 & 98 & 98.41 & 72.25 \\
\hline F5 & 5 & 0 & 0 & 97 & 93.25 & 76.5 \\
\hline F6 & 6 & 0 & -1 & 96 & 89.55 & 62.92 \\
\hline F8 & 8 & -1 & 0 & 97 & 93.25 & 63.65 \\
\hline F9 & 9 & -1 & -1 & 90 & 98.29 & 66.06 \\
\hline
\end{tabular}

Table 9: ANOVA table for the dependent variable (\% yield) from $3^{2}$ factorial designs

\begin{tabular}{lllllll}
\hline Source & $\begin{array}{l}\text { Sum of } \\
\text { squares }\end{array}$ & Df & $\begin{array}{l}\text { Mean } \\
\text { square }\end{array}$ & F value & $\begin{array}{l}\text { p value } \\
\text { Prob.>F }\end{array}$ & \\
\hline Model & 43.08 & 3 & 14.36 & 7.47 & $<0.05$ & Significant \\
A-drug & 10.67 & 1 & 10.67 & 5.55 & $<0.05$ & \\
B-carrier & 20.17 & 1 & 20.17 & 10.49 & $<0.05$ & \\
AB & 12.25 & 1 & 12.25 & 6.37 & $<0.05$ & \\
Pure error & 0.0000 & 2 & 0.0000 & & & \\
Cor total & 56.55 & 10 & & & & \\
\hline
\end{tabular}

Table 10: Statistical data for selected factorial model

\begin{tabular}{ll}
\hline Parameter & Value \\
\hline Regression coefficient $\left(\mathrm{R}^{2}\right)$ & 0.7619 \\
Adjusted Regression coefficient (adjusted $\mathrm{R}^{2}$ ) & 0.6599 \\
Predicted $^{2}$ & 0.0538 \\
Coefficient of variation (\%) & 1.44 \\
Adeq precision & 8.569 \\
\hline
\end{tabular}

Table 11: ANOVA table for the dependent variable (percent drug loading) from $3^{2}$ factorial designs

\begin{tabular}{lllllll}
\hline Source & $\begin{array}{l}\text { Sum of } \\
\text { squares }\end{array}$ & df & $\begin{array}{l}\text { Mean } \\
\text { square }\end{array}$ & F value & $\begin{array}{l}\text { p value } \\
\text { Prob. }>\text { F }\end{array}$ & \\
\hline Model & 111.56 & 7 & 15.94 & 41.54 & $<0.005$ & Significant \\
A-drug & 17.58 & 1 & 17.58 & 45.83 & $<0.005$ & \\
B-carrier & 39.25 & 1 & 39.25 & 102.30 & $<0.005$ & \\
$\mathrm{AB}$ & 1.04 & 1 & 1.04 & 2.71 & $<0.005$ & \\
$\mathrm{~A}^{2}$ & 34.22 & 1 & 34.22 & 89.20 & $<0.005$ & \\
$\mathrm{~B}^{2}$ & 5.26 & 1 & 5.26 & 13.70 & $<0.005$ & \\
$\mathrm{~A}^{2} \mathrm{~B}$ & 16.95 & 1 & 16.95 & 44.17 & $<0.005$ & \\
$\mathrm{AB}^{2}$ & 14.65 & 1 & 14.65 & 38.19 & $<0.005$ & \\
Pure error & 0.0000 & 2 & 0.0000 & & & \\
Cor total & 112.71 & 10 & & & & \\
\hline
\end{tabular}

Effect of independent variables (amount of drug and amount of carrier) on dependent variable percent drug loading and percent drug release at $30 \mathrm{~min}$

The analysis of the statistical parameters also showed that the selected model is significant. The results of the ANOVA for both the response
Table 12: ANOVA table for the dependent variable (percent drug release) from $3^{2}$ factorial designs

\begin{tabular}{lllllll}
\hline Source & $\begin{array}{l}\text { Sum of } \\
\text { squares }\end{array}$ & $\begin{array}{l}\text { Df } \\
\text { Mean }\end{array}$ & $\begin{array}{l}\text { F value } \\
\text { square }\end{array}$ & $\begin{array}{l}\text { p value } \\
\text { Prob>F }\end{array}$ & \\
\hline Model & 2720.23 & 7 & 388.60 & 138.36 & 0.0009 & Significant \\
A-drug & 0.1104 & 1 & 0.1104 & 0.0393 & 0.8555 & \\
B-carrier & 43.52 & 1 & 43.52 & 15.50 & 0.0292 & \\
$\mathrm{AB}$ & 250.11 & 1 & 250.11 & 89.05 & 0.0025 & \\
$\mathrm{~A}^{2}$ & 289.64 & 1 & 289.64 & 103.13 & 0.0020 & \\
$\mathrm{~B}^{2}$ & 123.87 & 1 & 123.87 & 44.10 & 0.0070 & \\
$\mathrm{~A}^{2} \mathrm{~B}$ & 157.47 & 1 & 157.47 & 56.07 & 0.0049 & \\
$\mathrm{AB}^{2}$ & 312.02 & 1 & 312.02 & 111.09 & 0.0018 & \\
Pure error & 0.0000 & 2 & 0.0000 & & & \\
Cor total & 2728.65 & 10 & & & & \\
\hline
\end{tabular}

Table 13: Statistical data for selected factorial model

\begin{tabular}{lll}
\hline Parameter & $\begin{array}{l}\text { Percent drug } \\
\text { loading }\end{array}$ & $\begin{array}{l}\text { Percent drug } \\
\text { release at 30 min }\end{array}$ \\
\hline $\begin{array}{l}\text { Regression coefficient }\left(\mathrm{R}^{2}\right) \\
\text { Adjusted Regression }\end{array}$ & 0.9898 & 0.9969 \\
coefficient (adjusted $\left.\mathrm{R}^{2}\right)$ & 0.9660 & 0.9897 \\
$\begin{array}{l}\text { Predicted } \mathrm{R}^{2} \\
\text { Coefficient of variation }\end{array}$ & 0.2975 & 0.6077 \\
Adeq precision & 0.6469 & 2.54 \\
\hline
\end{tabular}

variables (i.e., percent drug loading and percent drug release at $30 \mathrm{~min}$ ) for the selected model are shown in Tables 11 and 12. Responses, namely, percent drug loading and percent drug release at $30 \mathrm{~min}$ were studied. The model F-value obtained was 41.54, 138.36 for the response variables percent drug loading and percent drug release, respectively, which implied that the model is significant. In this case, $A, B, A^{2}, B^{2}, A^{2} B$, and $A B^{2}$ are significant model terms for the response variable percent drug loading and $\mathrm{B}^{2}, \mathrm{AB}, \mathrm{A}^{2}, \mathrm{~B}^{2}, \mathrm{~A}^{2} \mathrm{~B}$, and $\mathrm{AB}^{2}$ are significant model terms for the response variable percent drug release at $30 \mathrm{~min}$. The results of the statistical parameters for the selected model are presented in Table 13. The optimized equation for the model for the response variable (Y1) is given as follows.

$\%$ Drug loading $(\mathrm{Y} 2)=+92.97+2.97 * \mathrm{~A}($ drug $)+4.43 * \mathrm{~B}$ (carrier) $+0.5100 * \mathrm{~A}($ drug $) \mathrm{B}($ carrier $)+3.68 * \mathrm{~A}^{2}(\mathrm{drug})+1.44 * \mathrm{~B}^{2}$ (carrier) $-3.56 * \mathrm{~A}^{2}$ (drug) $\mathrm{B}$ (carrier) $-3.31 * \mathrm{~A}$ (drug) $\mathrm{B}^{2}$ (carrier) 


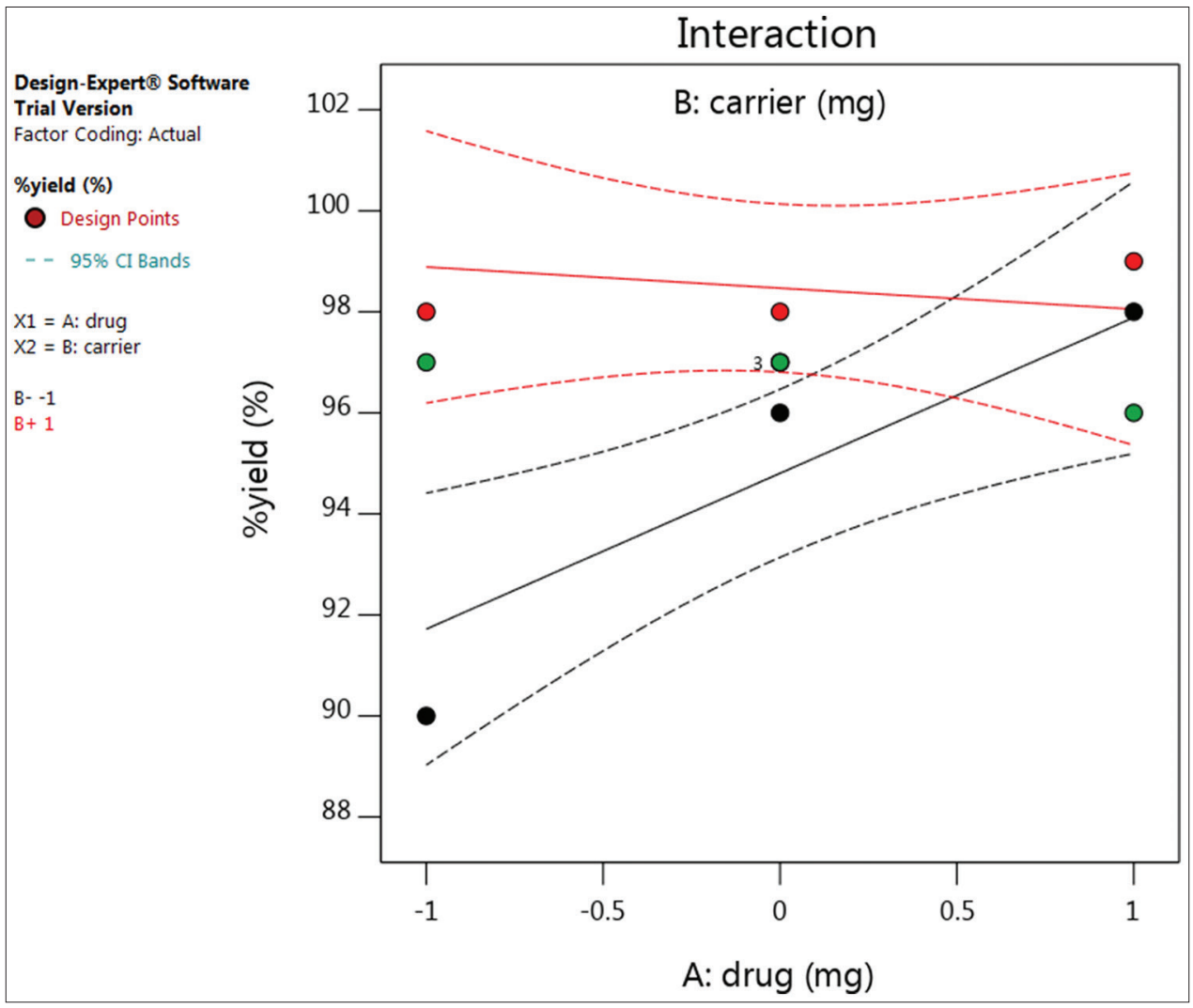

Fig. 5: Diagrammatic representation of the interaction of carrier and drug on percent yield

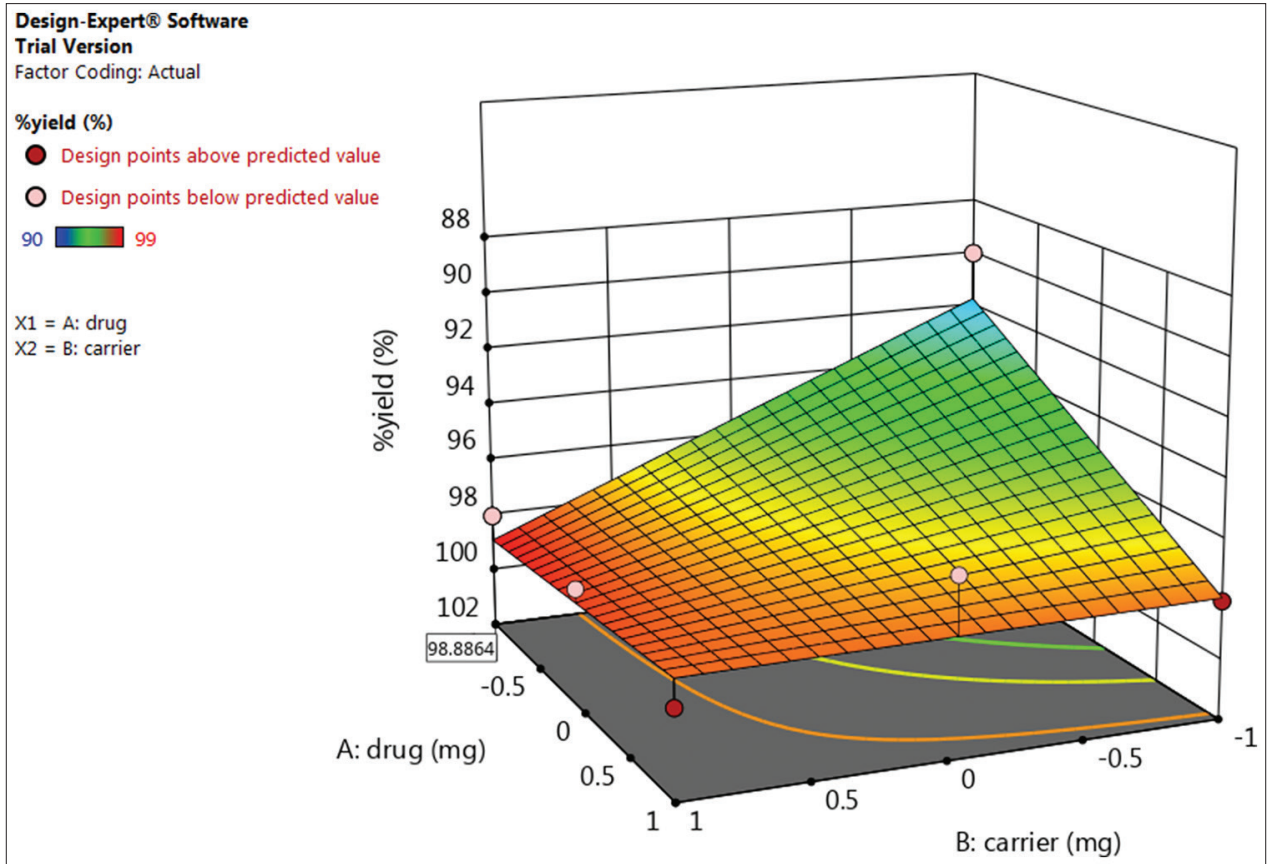

Fig. 6: 3D surface response plot of percentage yield

$\%$ Drug release at $30 \min (\mathrm{Y3})=+75.73+0.2350 * \mathrm{~A}(\mathrm{drug})+$ $4.67 * \mathrm{~B}($ carrier $)+7.91 * \mathrm{~A}$ (drug) $\mathrm{B}($ carrier $)-10.69 * \mathrm{~A}^{2}$ (drug) $-6.99 * B^{2}$ (carrier) $+10.87 * A^{2}$ (drug) $B($ carrier) $-15.30 * A$ (drug) $\mathrm{B}^{2}$ (carrier)

It is observed from the Equation no. 2 that the coefficient B1, B2, B1b2, $B 1^{2}$, and $B 2^{2}$ are positive and coefficient $B 1^{2} \mathrm{~B} 2$ and $\mathrm{B} 1 \mathrm{~B} 2^{2}$ are negative. It implies that interaction between drug and carrier. Equation 3 signifies that the coefficient $\mathrm{B} 1, \mathrm{~B} 2, \mathrm{~B} 1 \mathrm{~B} 2$, and $\mathrm{B} 1^{2} \mathrm{~B} 2$ are positive and coefficient $\mathrm{B}^{2}{ }^{2}, \mathrm{~B}^{2}$, and $\mathrm{B} 1 \mathrm{~B}^{2}$ are negative. A negative sign indicates the interaction between both parameters. An interaction plot and 3D surface response plot generated by Design Expert Software are represented in Figs. 7-10 for percent drug loading and percent drug release at $30 \mathrm{~min}$, respectively. In case of percent drug loading, interaction plot shows that the high level of the carrier has a positive effect on the response variable at varied levels of the drug whereas the low level has a strong negative 


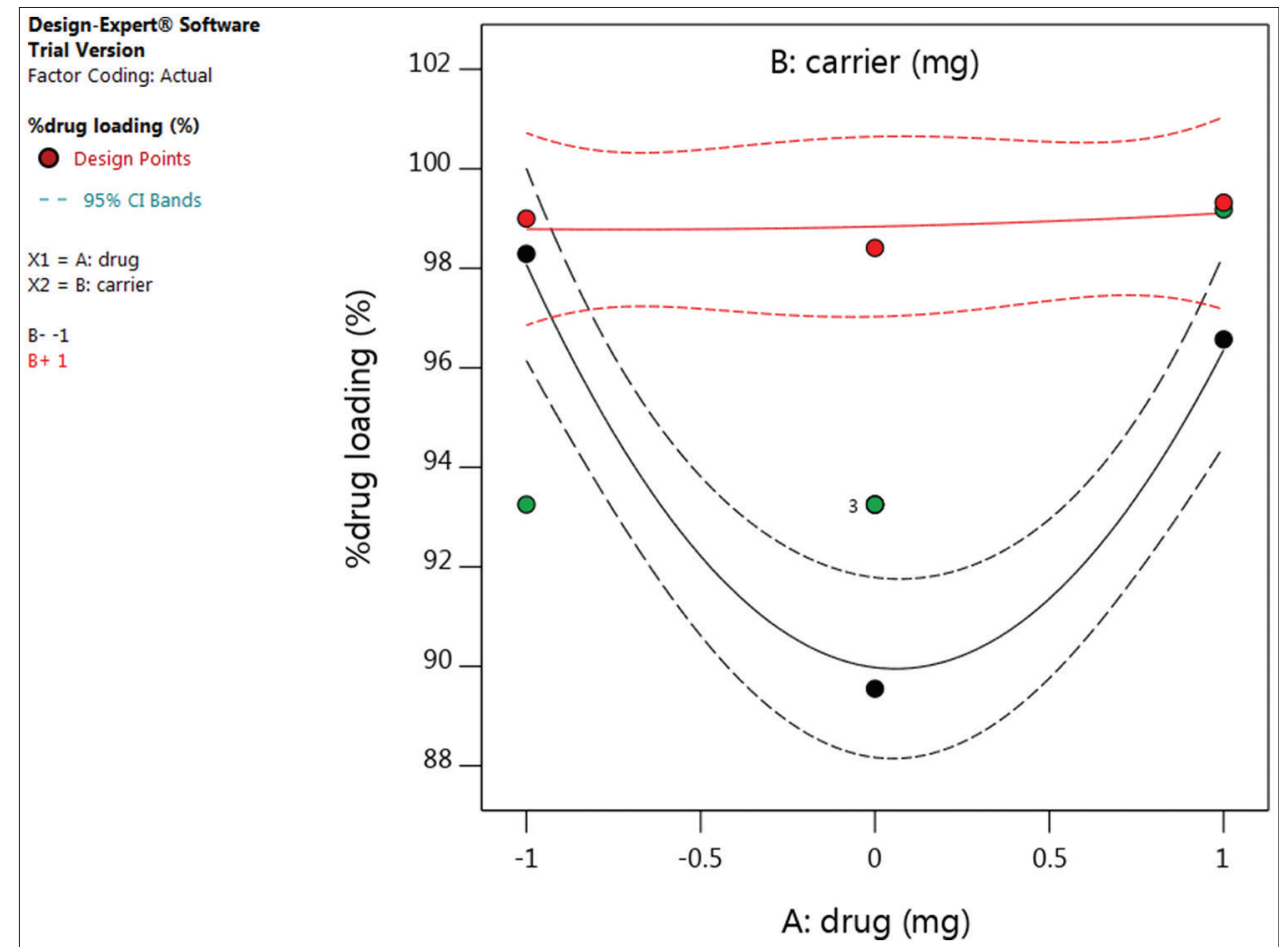

Fig. 7: Diagrammatic representation of the interaction of carrier and drug on percent drug loading

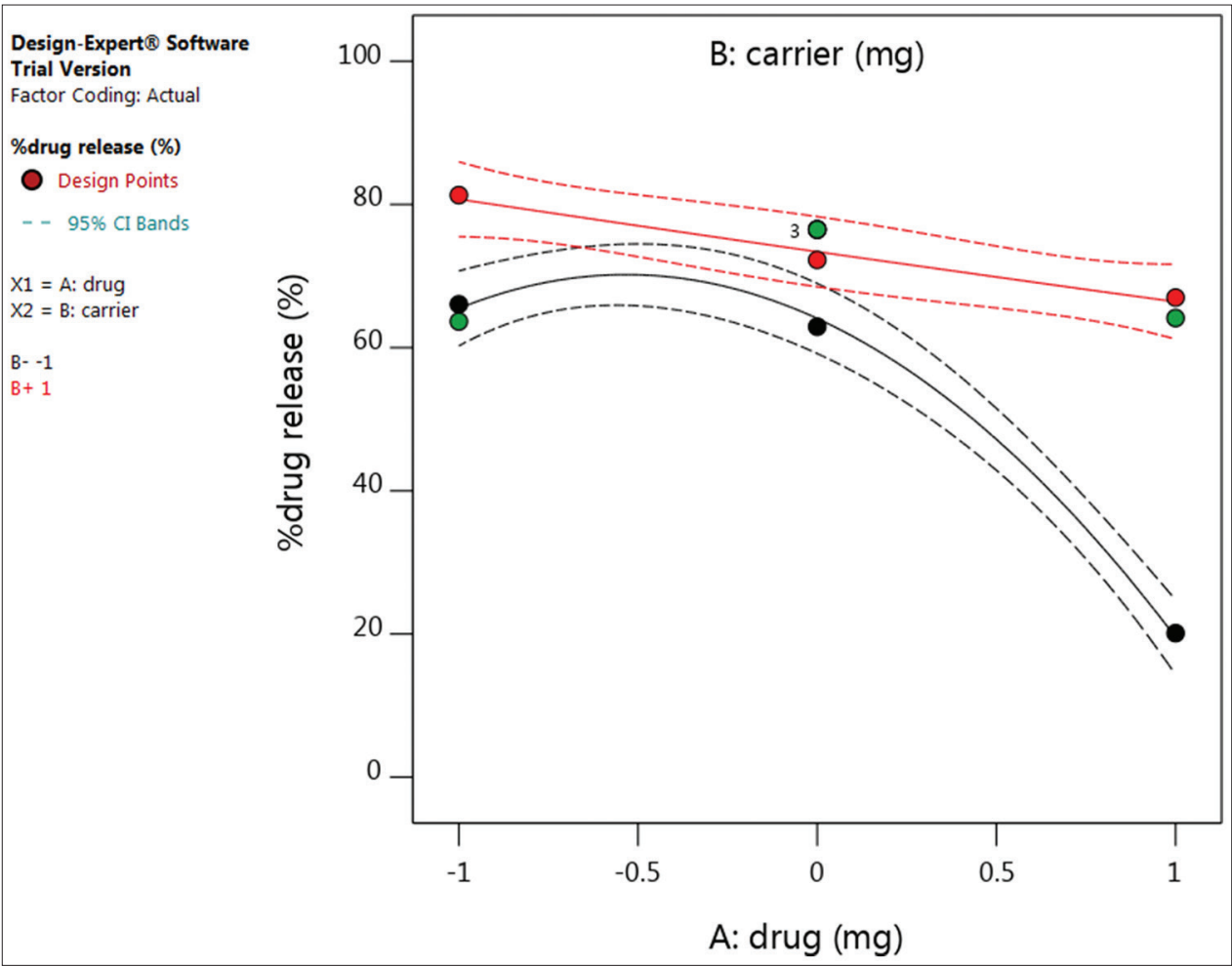

Fig. 8: Diagrammatic representation of the interaction of carrier and drug on percent drug release at $30 \mathrm{~min}$

effect with the increased amounts of the drug. In case of percent drug release at $30 \mathrm{~min}$, interaction plot shows that the high level of the carrier has a positive effect on the response variable at the low level of the drug whereas the low level of the carrier has a strong negative effect on the response variable at a high level of the drug.

The 3D surface plot shows the responses in a 3D view. In the case of percent drug loading, it was observed that the downward trend of wire mesh was at a high level of drug and low level of carrier, upward trend of wire mesh was at high of carrier and low of drug and the other two responses (i.e., High of drug and high of carrier and low of drug and low of carrier) also positions toward upward. It is predicted that the dependent variable is directly proportional to the amount of carrier. Whereas in case of percent drug release at $30 \mathrm{~min}$, it was observed that the downward trend of wire mesh was at a low level of the carrier and high level of the drug, and the upward trend of wire mesh was at a high level of the carrier and low level of the drug. 


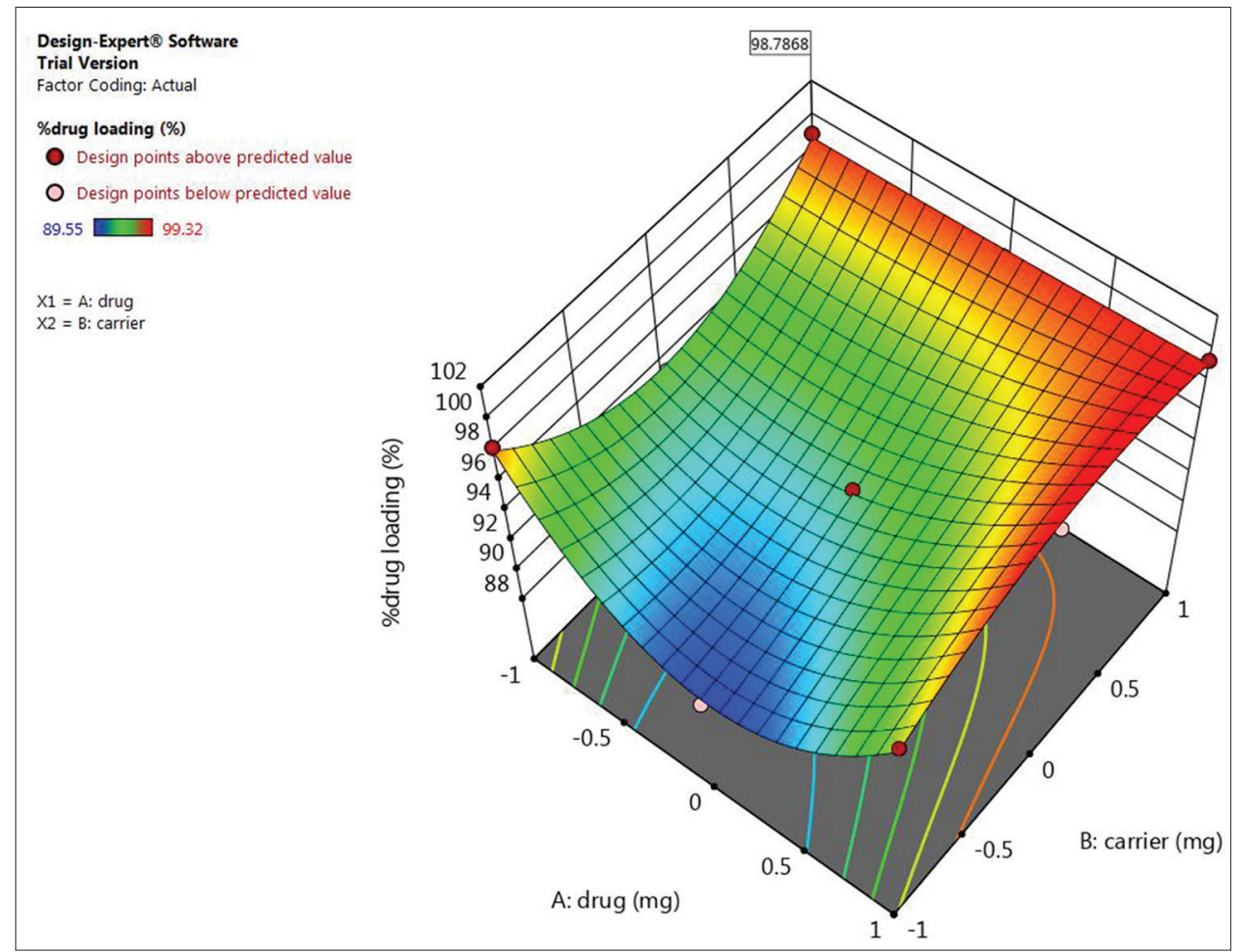

Fig. 9: 3D surface response plot of percent drug loading

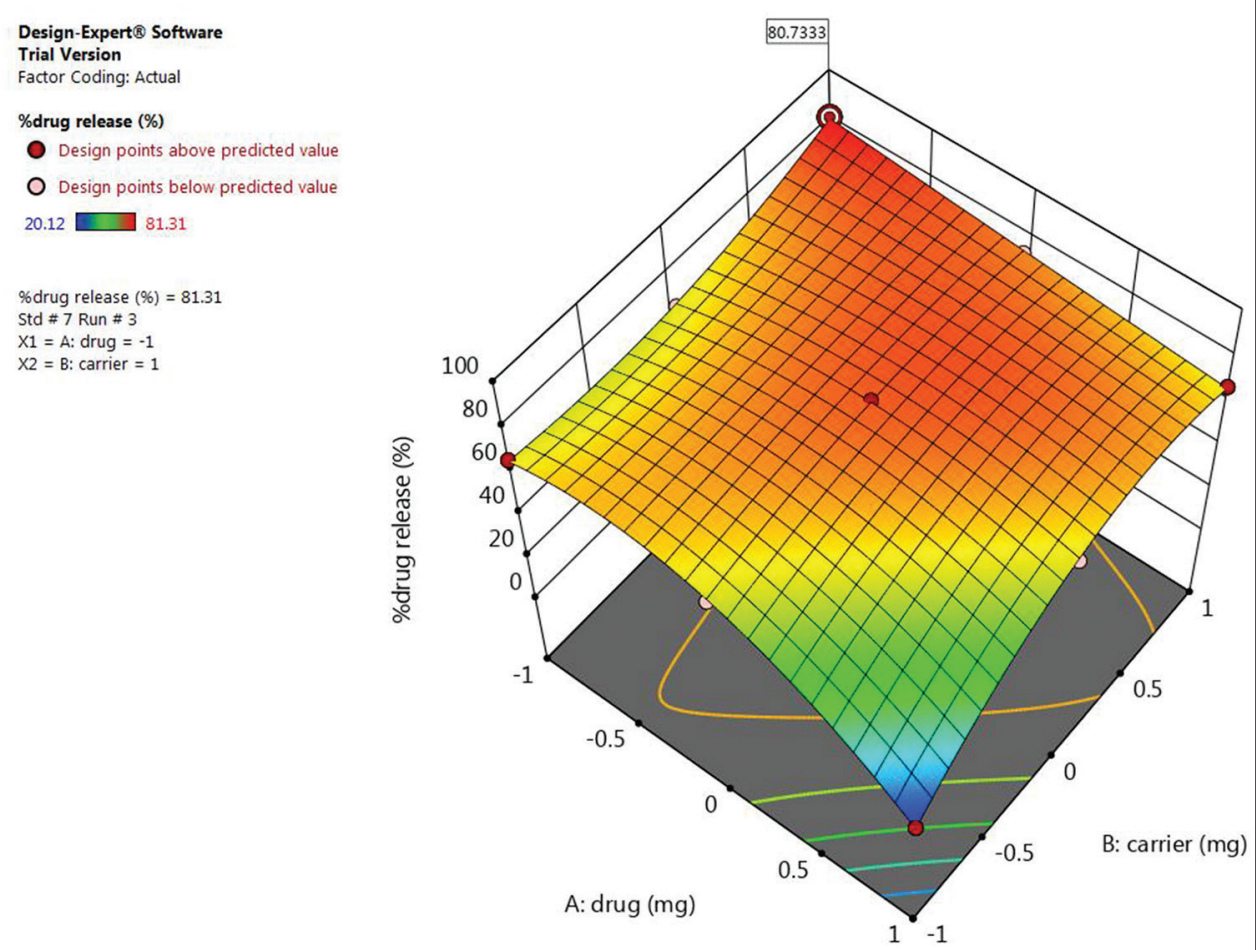

Fig. 10: 3D surface response plot of percent drug release

To optimize all the responses with different targets, a multicriteria decision approach, a numerical optimization technique by the desirability function (Fig. 11), and a graphical optimization technique by the overlay plot (Fig. 12) were used. The optimized formulation was obtained by applying constraints on dependent variable responses (percent yield, percent drug loading, and percent drug release at $30 \mathrm{~min}$ ) and independent variables (drug and carrier). The recommended concentrations of the drug and carrier were calculated by the Design-Expert software from the overlay plot and the desirability plot which has the highest desirability near to 1.0 .

The study design after optimization showed 100 solutions from which one solution giving maximum drug release with good drug loading and 


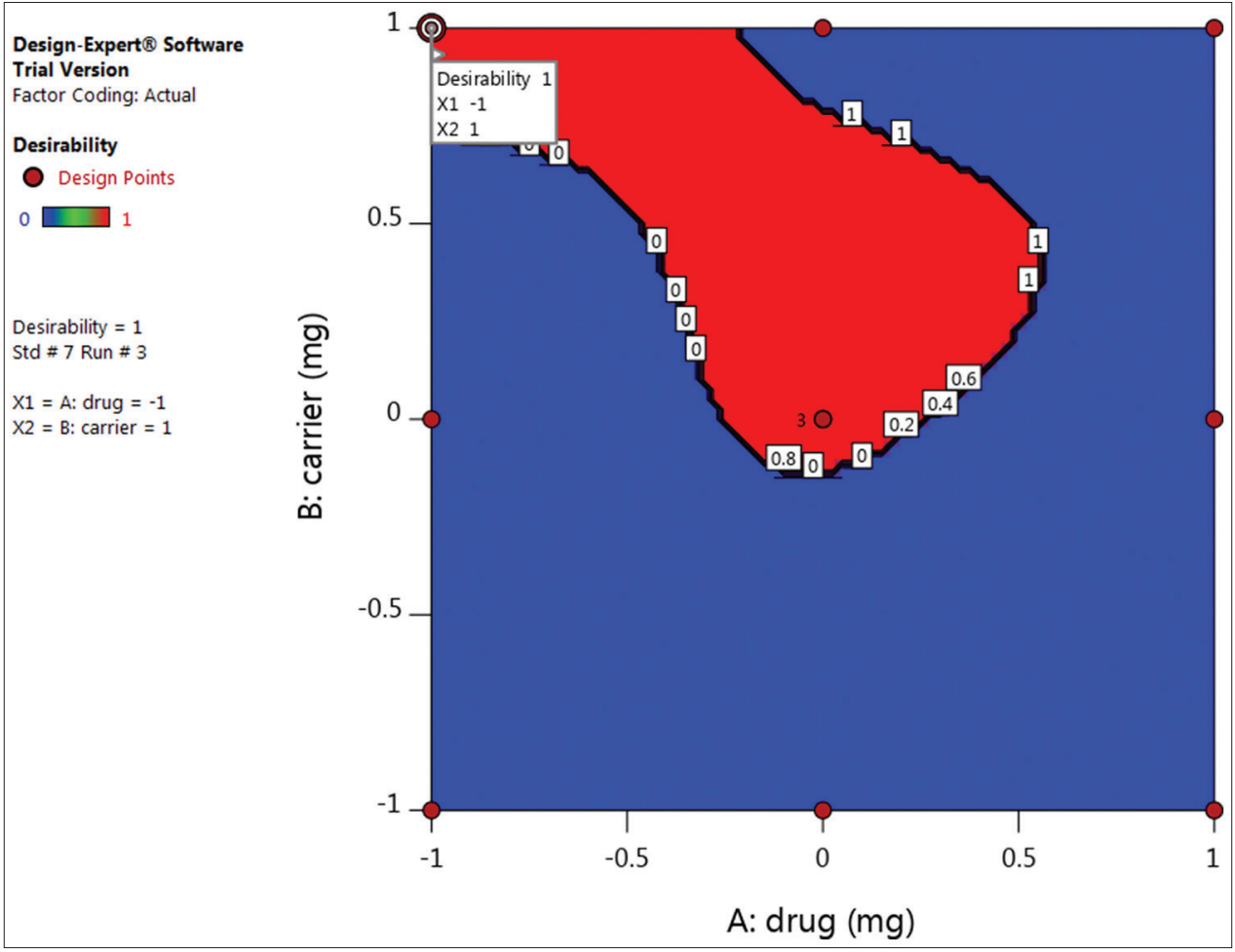

Fig. 11: Desirability plot for the optimization of drug-carrier concentration

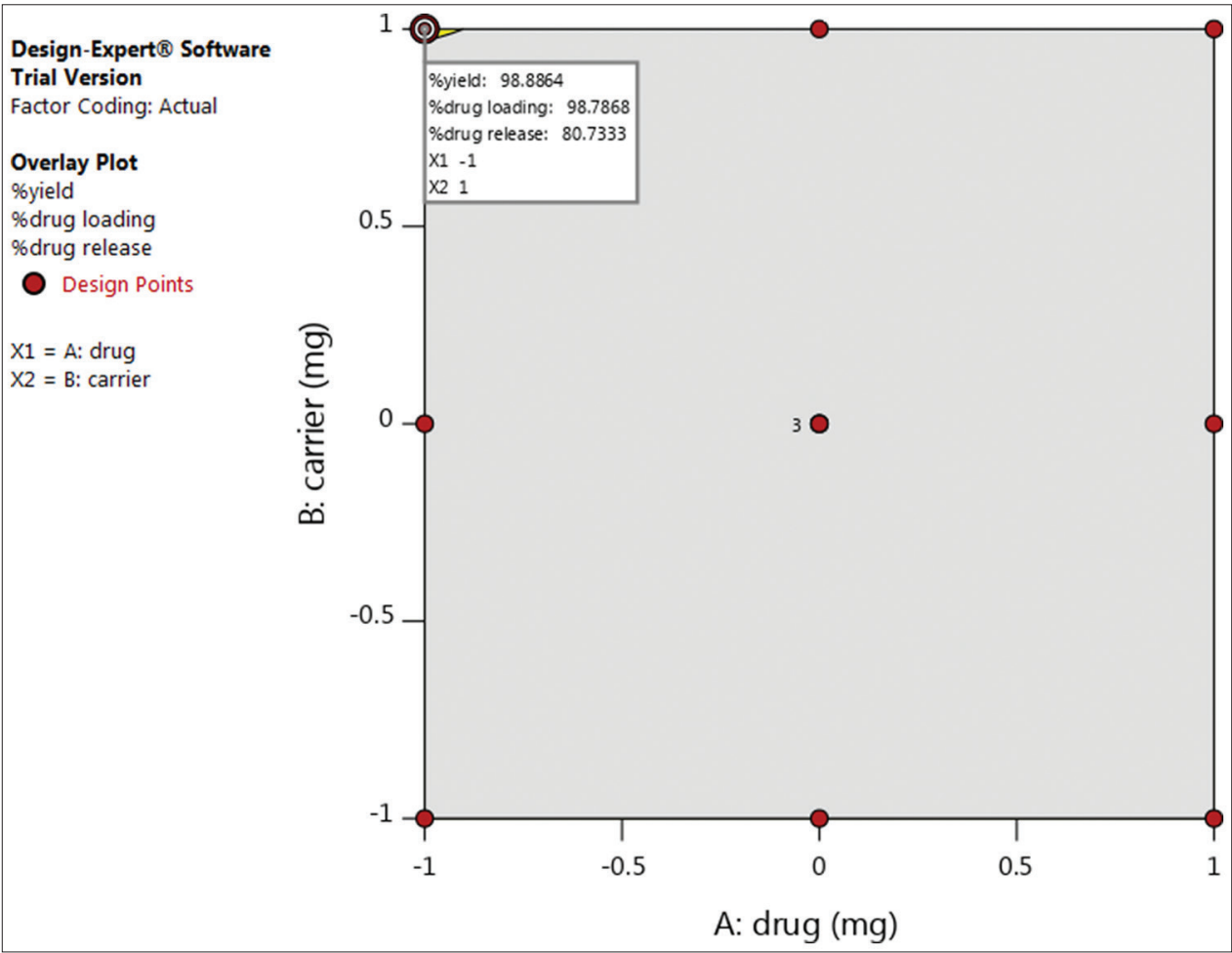

Fig. 12: Overlay plot of the constraints applied to the study design

percent yield was selected and studied validation of the model. The batch F7 showed optimum results as predicted.

\section{Evaluation of batches for optimization of the amount of carrier}

The batches of factorial design study were evaluated for drug loading and drug release from adsorbate. The results for the drug loading and drug release from the carrier are given in Table 14.
Fig. 13 shows that the drug release is more from batch F7 (81.31\%) in 30 min followed by batch F5 (76.5\%) and F4 (72.25\%). The drug release from batch F3 is less $(20.12 \%)$. This implies that more the amount of carrier taken for adsorption more the drug release in lesser time. Batch F3 shows slow release because of loading high amount of drug on less amount of carrier. 


\begin{tabular}{lll}
\hline Batch & GLB & Syloid XDP 3050 \\
\hline F1 & +1 & +1 \\
F2 & +1 & 0 \\
F3 & +1 & -1 \\
F4 & 0 & +1 \\
F5 & 0 & 0 \\
F6 & 0 & -1 \\
F7 & -1 & +1 \\
F8 & -1 & 0 \\
F9 & -1 & -1 \\
\hline
\end{tabular}

Characterization of the optimized batch

Characterization of the optimized batch by X-ray diffraction

The PXRD pattern of an optimized batch of GLB loaded Syloid XDP 3050 is represented in Fig. 14. The XRD pattern did not show any diffraction

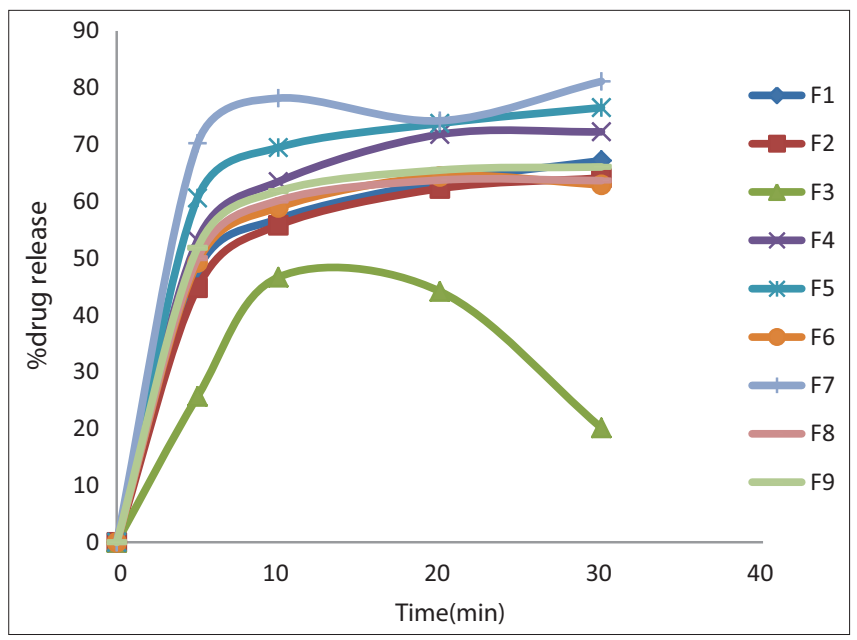

Fig. 13: Drug release profile of the adsorbate of the factorial batches peaks that are characteristic of the crystalline form of the drug. It implies that the drug changed its polymorphic form and converted to the amorphous form.

\section{Characterization of the optimized batch of an adsorbed drug by SEM}

Fig. 15 depicts the morphology of GLB-loaded Syloid XDP3050. Drug adsorption can be seen on the surface of Syloid. The irregular shaped the crystalline structure of GLB is lost, indicating a change in its polymorphic form.

Characterization of the optimized batch of an adsorbed drug by DSC DSC thermogram of batch F7 showed in Fig. 16 further confirmed the loss of crystallinity of GLB after loading onto Syloid XDP 3050. As compared with pure GLB, changes in melting point, peak onset ultimately proved that GLB was loaded on and/or into Syloid XDP 3050 .

Evaluation of formulation development of tablets using the adsorbed drug

The drug-mesoporous silica adsorbate exhibited excellent flow properties and compressibility. Thus, in this work, the direct compression method was adopted to prepare tablets. All the excipients used were of direct compression grade. Superdisintegrants (namely, sodium starch glycolate and croscarmellose sodium) were used in tablet formulation as they have the ability to rapidly disintegrate tablet thereby facilitating an immediate drug release. HPMC E 5 was used as a stabilizer in the formulation to inhibit the precipitation of drug in the dissolution medium.

Evaluation of pre-compression parameters of the blend

Blends B1 and B2 were evaluated for flow properties. Results of the flow characteristics are shown in Table 15. It was observed that both batches B1 and B2 showed good flow, as depicted in Table 15. From the results, it can be thus concluded that all the blends possess suitable compressibility and can be tableted using direct compression technique.

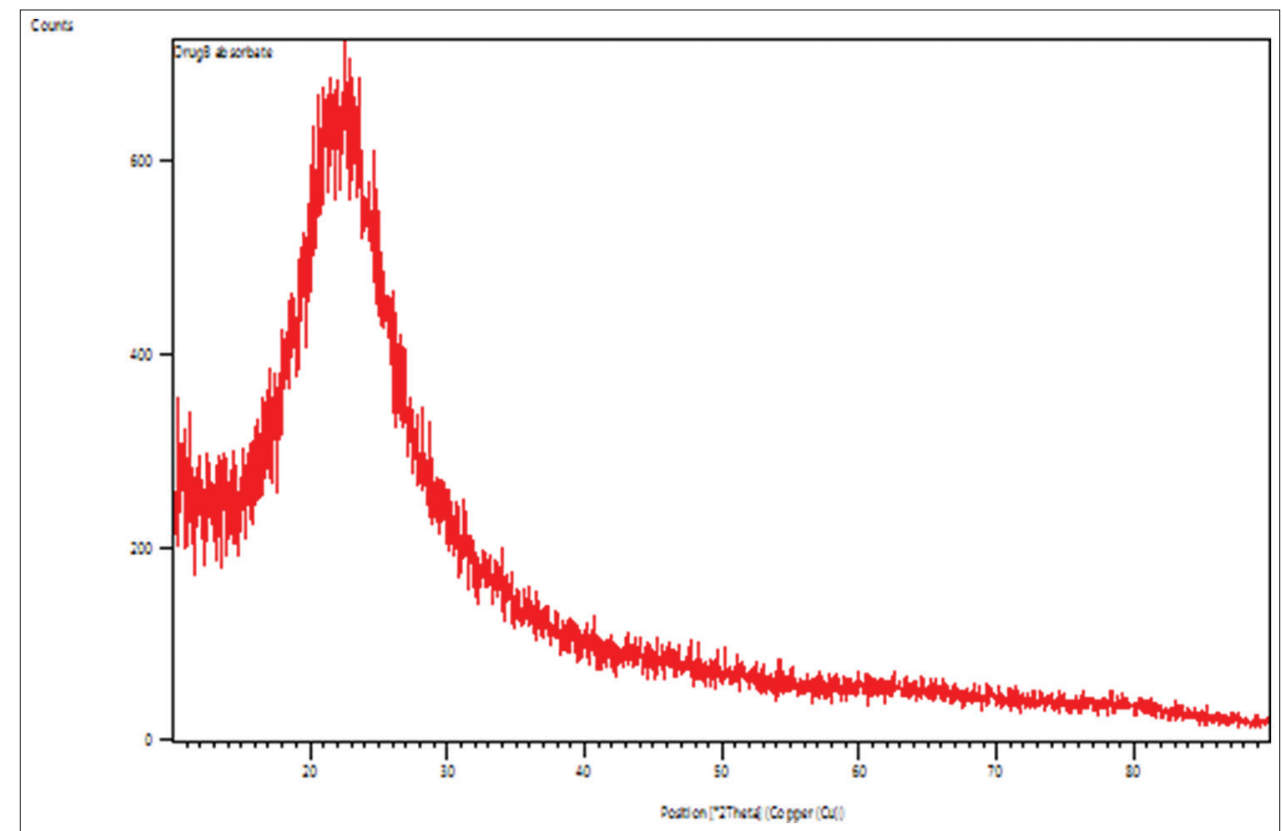

Fig. 14: X-ray diffraction pattern of the optimized batch of drug adsorbate

Table 14: Results for factorial batches

\begin{tabular}{|c|c|c|c|c|c|c|c|c|c|}
\hline Parameters & F1 & F2 & F3 & F4 & F5 & F6 & F7 & F8 & F9 \\
\hline Percent drug loading & 99.32 & 99.18 & 96.57 & 98.41 & 93.25 & 89.55 & 99 & 93.25 & 98.29 \\
\hline Percent drug release at $30 \mathrm{~min}$ & 67.17 & 64.12 & 20.12 & 72.25 & 76.50 & 62.92 & 81.31 & 63.65 & 66.06 \\
\hline
\end{tabular}


Evaluation of post-compression parameters of the tablets

The pre-compression blends were compressed to form tablets using a mini-press 12 station tablet compression machine using $6 \mathrm{~mm}$ punch

Table 15: Pre-compression evaluation of batches B1 and B2

\begin{tabular}{lll}
\hline Parameters & B1 & B2 \\
\hline Bulk density $(\mathrm{g} / \mathrm{ml})$ & 0.357 & 0.344 \\
Tapped density $(\mathrm{g} / \mathrm{ml})$ & 0.434 & 0.434 \\
Carr's index $(\%)$ & 17.85 & 20.68 \\
Hausner's ratio & 1.21 & 1.26 \\
Angle of repose $\left(^{\circ}\right)$ & 21.53 & 21.41 \\
Inference & Good flow & Good flow \\
\hline
\end{tabular}

Table 16: Post-compression evaluation of batch B1 and B2

\begin{tabular}{llc}
\hline Physical parameters & B1 & B2 \\
\hline Appearance & Circular, biconvex, white tablets \\
Average weight & 98 & 101 \\
Average thickness & 3.42 & 3.46 \\
Average hardness & $4-5$ & $4-5$ \\
Disintegration & 7 min 45 s & 9 min 24 s \\
Weight variation & Complies & Complies \\
Friability (\%) & 0.46 & 0.23 \\
Assay (\%) & $98.37 \pm 2.31$ & $97.21 \pm 1.28$ \\
\hline
\end{tabular}

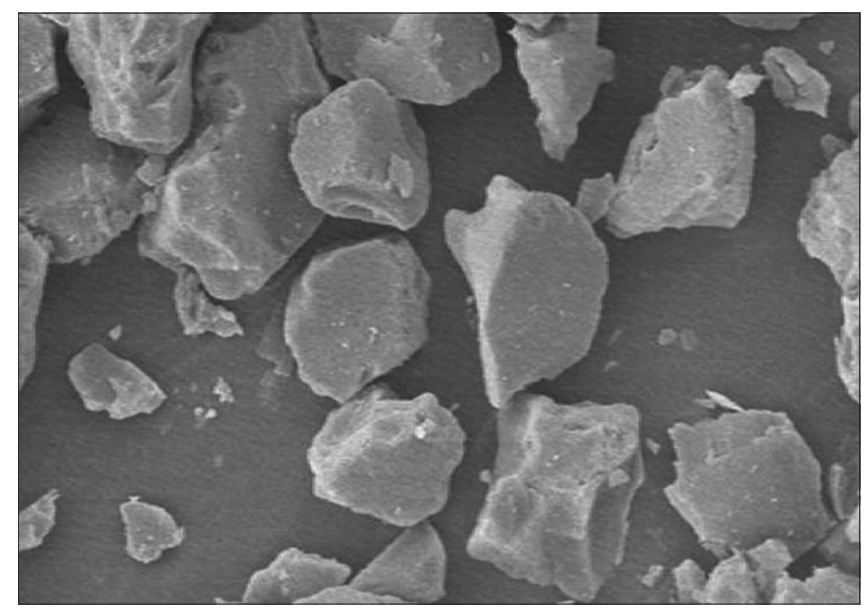

Fig. 15: Scanning electron microscopy of drug adsorbate of biconcave, circular shape. The compressed tablets were evaluated for physical parameters, assay, and in vitro drug release profile studies.

\section{Physical parameters}

Results of the physical evaluation of the post-compression parameters are shown in Table 16. The results show that the physical parameters of all the trial batches were found to be within limits.

Assay

Results of the content uniformity of the trial batches are represented in Table 16. The results are expressed in the form of mean \pm SD. All the batches showed above $90 \%$ drug content.

\section{In vitro dissolution studies of batches $B 1$ and B2}

In vitro drug release study was performed on the tablets as per the procedure mentioned in the section of evaluation of drug release from the drug-carrier complex. Drug release profiles from the batches B1 to B2 are illustrated in Fig. 17. Drug release studies of tablets from batches B1 to B2 revealed that batches B2 containing HPMC E5 showed maximum drug release at 30 min. Batch B1 without HPMC E5 showed least drug release.

Comparison of in vitro drug release profile of selected tablet and marketed tablet

In vitro drug release study was performed on the tablets as per the procedure mentioned in the section of evaluation of drug release from the drug-carrier complex. Fig. 18 showed a graphical representation of drug release profiles of both tablets.

The graphical representation showed that within $30 \mathrm{~min}$, the $86 \%$ drug released from formulated tablet, whereas marketed tablet showed only $34.93 \%$ drug release after $30 \mathrm{~min}$.

\section{CONCLUSION}

The solubility of GLB was enhanced by loading onto SYLOID ${ }^{\circledR}$ XDP 3050 matrix. Furthermore, the dissolution profile of GLB-loaded SYLOID ${ }^{\circledR}$ XDP 3050-containing tablets was also improved as compared with conventional and commercially available GLB tablets. This study indicates that non-ordered mesoporous SYLOID ${ }^{\circledR}$ XDP 3050 is a promising carrier, which enhances the oral bioavailability of poorly water-soluble drugs. Preparing a tablet dosage form containing drugloaded silica may represent a new approach for the development of better absorbed oral formulations for poorly soluble drugs.

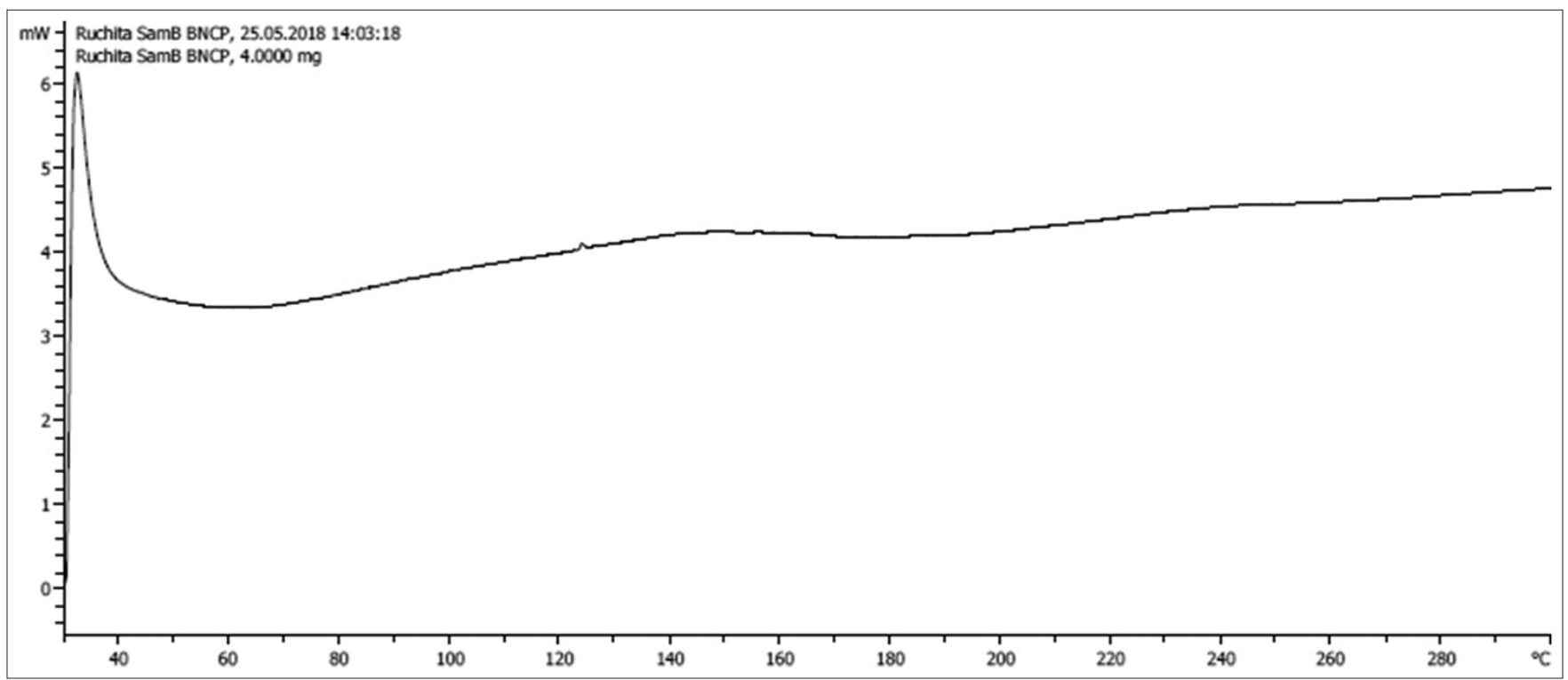

Fig. 16: Differential scanning calorimeter spectrum of batch A7 


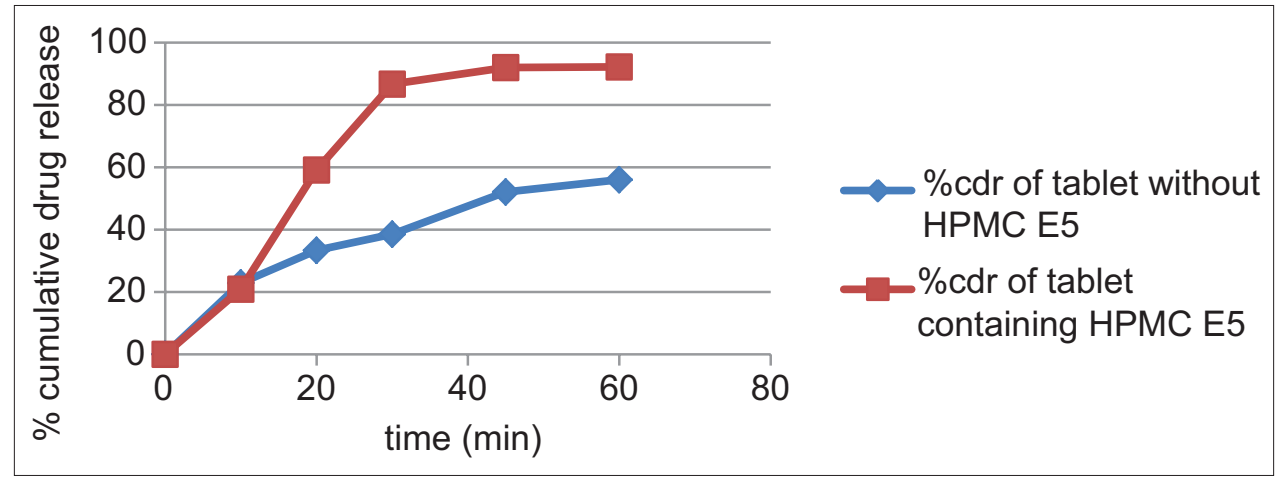

Fig. 17: In vitro drug release studies on tablet batches B1 and B2

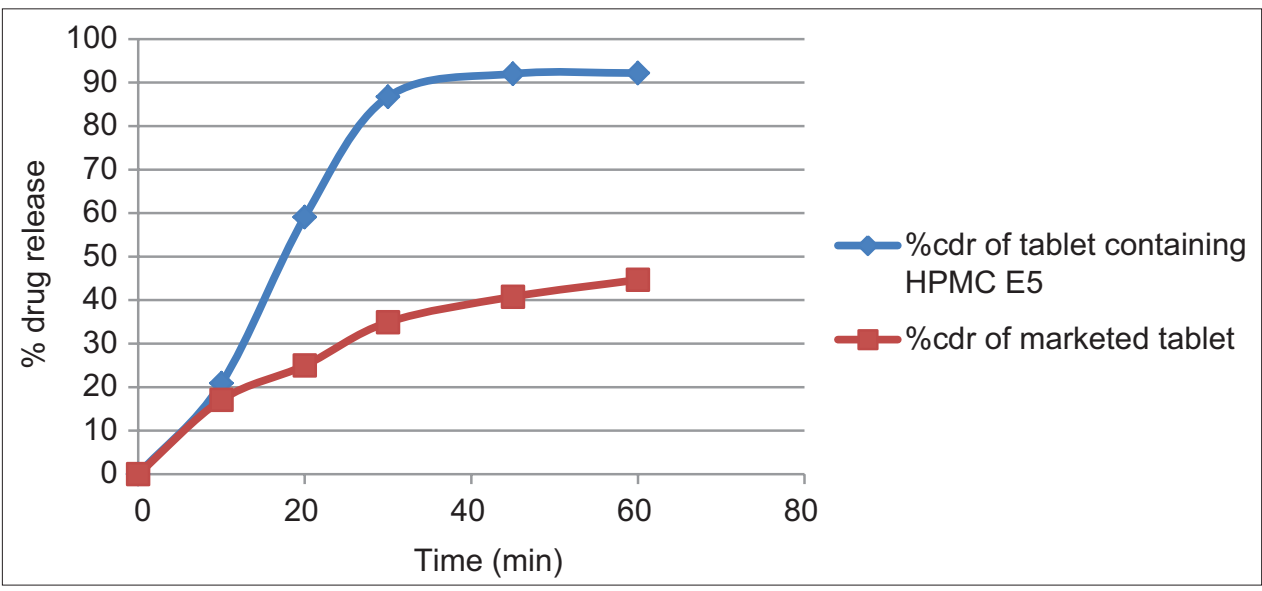

Fig. 18: Dissolution profiles of formulated tablet and marketed table

Conclusively, the current study attained the successful design, preparation, and evaluation of drug-loaded SYLOID $^{\circledR}$ XDP 3050-containing GLB tablets.

\section{AUTHORS' CONTRIBUTION}

Dr. Swati Miittal designed the experimental study and performed the statistical analysis. Akshay Sonawane and Mangesh Khune carried out the experimental part and participated in the sequencing alignment and drafted the manuscript.

\section{CONFLICTS OF INTEREST}

The authors declare that they have no conflicts of interest.

\section{REFERENCES}

1. Vo CL, Park C, Lee BJ. Current trends and future perspectives of solid dispersions containing poorly water-soluble drugs. Eur J Pharm Biopharm 2013;85:799-813

2. Kawabata Y, Wada K, Nakatani M, Yamada S, Onoue S. Formulation design for poorly water-soluble drugs based on biopharmaceutics classification system: Basic approaches and practical applications. Int J Pharm 2011;420:1-0

3. Xu W, Riikonen J, Lehto VP. Mesoporous systems for poorly soluble drugs. Int J Pharm 2013;453:181-97.

4. Kurtagic H, Memic M, Selovic A. Effect of particle size on the dissoluton of glibenclamde. Int J Pharm Pharm Sci 2013;5:775-9.

5. Savjani KT, Gajjar AK, Savjani JK. Drug solubility: Importance and enhancement techniques. ISRN Pharm 2012;2012:195727.

6. O'Shea JP, Nagarsekar K, Wieber A, Witt V, Herbert E, O’Driscoll CM, et al. Mesoporous silica-based dosage forms improve bioavailability of poorly soluble drugs in pigs: Case example fenofibrate. J Pharm Pharmacol 2017;69:1284-92.

7. Tahvanainen M, Rotko T, Mäkilä E, Santos HA, Neves D, Laaksonen T, et al. Tablet preformulations of indomethacin-loaded mesoporous silicon microparticles. Int J Pharm 2012;422:125-31.

8. Van Speybroeck M, Mols R, Mellaerts R, Thi TD, Martens JA, Van Humbeeck J, et al. Combined use of ordered mesoporous silica and precipitation inhibitors for improved oral absorption of the poorly soluble weak base itraconazole. Eur J Pharm Biopharm 2010;75:354-65.

9. Guzmán HR, Tawa M, Zhang Z, Ratanabanangkoon P, Shaw P, Gardner CR, et al. Combined use of crystalline salt forms and precipitation inhibitors to improve oral absorption of celecoxib from solid oral formulations. J Pharm Sci 2007;96:2686-702.

10. Brouwers J, Brewster ME, Augustijns P. Supersaturating drug delivery systems: The answer to solubility-limited oral bioavailability? J Pharm Sci 2009;98:2549-72.

11. Balaji A, Kumari MH. In vitro interaction studies between-lumefantrine and lamivudine/metonidazole. Int J Pharm Ind Res 2013;3:335-45.

12. Ingle VP, Talele GS. Comparative effect of metformin in combination with glimepiride and glibenclamide on lipid profile in Indian patients with Type 2 diabetes mellitus. Int J Pharm Pharm Sci 2011;3:472-4.

13. Nikghalb LA, Singh G, Singh G, Kahkeshan KF. Solid dispersion: Methods and polymers to increase the solubility of poorly soluble drugs. J Appl Pharm Sci 2012;2:170-5.

14. Sambasevam KP, Mohamad S, Sarih NM. Synthesis and characterization of the inclusion complex of $\beta$-cyclodextrin and azomethine. Int J Mol Sci 2013;14:3671-82.

15. McCarthy CA, Ahern RJ, Dontireddy R, Ryan KB, Crean AM. Mesoporous silica formulation strategies for drug dissolution enhancement: A review. Expert Opin Drug Deliv 2016;13:93-108. 